\title{
Thai trauma nurses' knowledge of neuro-protective nursing care of traumatic brain injury patients: A survey study
}

\author{
AUTHORS \\ Kesorn PROMLEK, RN, MNS (Adult Nursing) ${ }^{1,2}$ \\ Judy CURREY, RN, PhD ${ }^{1}$ \\ Jintana DAMKLIANG, RN, $\mathrm{PhD}^{2}$ \\ Julie CONSIDINE, RN, PhD ${ }^{1,3}$
}

${ }^{1}$ Deakin University Geelong, School of Nursing and Midwifery; Centre for Quality and Patient Safety Research; Institute for Health Transformation

${ }^{2}$ Faculty of Nursing, Prince of Songkla University, Thailand

${ }^{3}$ Centre for Quality and Patient Safety Research-Eastern Health Partnership, Box Hill, Victoria, Australia

\section{Correspondence}

Kesorn PROMLEK, School of Nursing and Midwifery, Deakin University, 221 Burwood Hwy, Burwood, Victoria 3125, Australia.

Email: kpromle@deakin.edu.au Tel.: +61 402885913

ORCID iD: Kesorn PROMLEK ID: https://orcid.org/0000-0002-1838-5522

\section{Author's institutional affiliations:}

This is the author manuscript accepted for publication and has undergone full peer review but has not been through the copyediting, typesetting, pagination and proofreading process, which may lead to differences between this version and the Version of Record. Please cite this article as doi: $10.1111 /$ nhs.12730

This article is protected by copyright. All rights reserved. 
- Faculty of Nursing, Prince of Songkla University, Thailand

- School of Nursing and Midwifery, Deakin University, Burwood campus, Australia (a PhD student)

This article is protected by copyright. All rights reserved. 


\section{Acknowledgements}

The authors would like to thank nurses and nursing assistants from trauma ward for their participation in this study, as well as the Nurse Director of the hospital, Head Nurse of trauma ward, and an advanced practice nurse of neurosurgical ICU for their support.

\section{Conflict of interest}

No conflict of interest has been declared by the authors.

\section{Funding information}

Ms Promlek is supported by a PhD scholarship from Deakin University, Australia and Faculty of Nursing, Prince of Songkla University, Thailand, and a 2019 Deakin University Faculty of Health Publication Award.

\section{Authorship statement}

We confirm that all listed authors meet the authorship criteria according to the latest guidelines of the Internatinal Committee of Medical Journal editors and that all authors are in agreement with the content of the manuscript. $\mathrm{KP}, \mathrm{JCO}, \mathrm{JCu}$ conceived the study concept and design. KP collected the data and drafted the manuscript. KP, JCo, JCu were responsible for analysis and interpretation of data. JCo, JCu, and JD were responsible for critical revisions to the manuscript for important intellectual content. All authors approved the final version for submission. 
Word count: 3,898

\title{
Thai trauma nurses' knowledge of neuro-protective nursing care of traumatic brain injury patients: A survey study
}

\begin{abstract}
Thai trauma nurses play a vital role in neuro-protective nursing care of patients with moderate or severe traumatic brain injury. Nurses' knowledge of the evidence underpinning initial neuro-protective nursing care vital to safe and high quality patient care. However, the current state of knowledge of Thai trauma nurses is poorly understood. In this study, we investigated Thai nurses' knowledge of neuro-protective nursing care of patients with moderate or severe traumatic brain injury. Data were collected by a survey, comprising a section on participant characteristics and series of multiple-choice questions. All registered nurses $(n=22)$ and nursing assistants $(n=13)$ from trauma ward of a regional Thai hospital were invited to participate: the response rate was $100 \%$. Participants had limited knowledge of carbon dioxide monitoring; causes and implications of hypercapnia; mean arterial pressure and cerebral perfusion pressure targets; management of sedatives and analgesics; and management of hyperthermia. Improving their knowledge focusing on knowledge deficits through educational training and implementation of evidence-based practice is essential to
\end{abstract}


improve the safety and quality of care for Thai patients with moderate or severe traumatic brain injury.

KEYWORDS: brain injury; evidence-based nursing; knowledge; neuroprotection; trauma; Thailand 
Thai trauma nurses' knowledge of neuro-protective nursing care of traumatic brain injury patients: A survey study

\section{INTRODUCTION}

Moderate or severe traumatic brain injury (TBI) is a leading cause of death, disability, and socioeconomic burden worldwide (Douglas, Morarty, \& Saxena, 2011; Massenburg et al., 2017). The global incidence of TBI is estimated at 939 cases per 100,000 population and a leading cause of TBI is road traffic crashes (Dewan et al., 2019). The majority (93\%) of road traffic deaths occur in developing countries (World Health Organization [WHO], 2018), and road trauma is a critical issue in Thailand. The number of road traffic deaths in Thailand have increased (Bureau of Policy and Strategy, Thailand, 2017), and are highest among countries in South-East Asia at 32.7 per 100,000 population (WHO, 2018). The rate of TBI-related hospitalization increased from 78,375 in 2015 to 91,191 in 2017 (National Statistical Office of Thailand, 2019). Motorcycle riders without helmets are a group of Thai people who have high mortality following road traffic crashes (Office of Transport and Traffic Policy and Planning, Thailand, 2019) and 90\% of deaths in motorcycle riders are from moderate or severe TBI (Panjaisri, Phuenpathom, \& Veerasan, 2013).

\section{Background}

This article is protected by copyright. All rights reserved. 
Thai trauma nurses play a vital role in the initial neuro-protective nursing care of patients with moderate or severe TBI as the only healthcare professionals by the bedside 24 hours a day, seven days a week (Hurst, 2010). Nurses' role in the initial neuro-protective care of patients with moderate or severe TBI is multifaceted, for example, monitoring of patient's oxygenation and ventilation, intracranial pressure (ICP), cerebral perfusion pressure (CPP), and neurological assessment, and how nurses fulfil these responsibilities influences patient mortality and outcomes (Varghese, Chakrabarty, \& Menon, 2017). In Thailand, as a result of nursing shortages, the Thai Ministry of Public Health and the hospitals have deployed skill-mix models to recruit nursing assistants (NAs) to care for patients' basic needs under the supervision and guidance of registered nurses (RNs) (Bureau of Health Policy and Strategy, Thailand, 2016). In the Thai trauma ward context, NAs are responsible for essential nursing care such as obtaining vital signs, turning position, provision of hygiene, as well as using a self-inflating bag to assist nurses during the process of endotracheal suctioning. Thus, NAs are part of the workforce and have crucial involvement in caring for patients with moderate or severe TBI.

For the purpose of this study, initial neuro-protective nursing care is defined as the strategies that aim at preventing neuronal loss and neurodegeneration through applying agents to inhibit pathophysiological pathways that injuries to the brain after immediate trauma to the brain (Panahi et al., 2018). In Thailand, evidence-based clinical practice guidelines (CPGs) for TBI management were developed by an expert 
panel of neurosurgeons (Panjaisri et al., 2013), which there was no input to the CPG from nurses and other disciplines in the care of TBI patients. This CPG is focused on the neurosurgeon and physician role in the emergency department (ED) and referral systems from community hospitals that lack neurosurgeons, to tertiary care hospitals in which neurosurgeons are available. Little is known about the effectiveness of this CPG regarding its use and uptake, and its impact on clinical care. Specific guidelines for initial neuro-protective nursing care of patients with moderate or severe TBI for use in the Thai critical care context do not exist. The evidence-based knowledge of neuroprotective nursing care used in this study is therefore based on the recommendations from existing guidelines related to TBI care from developed countries.

Registered nurses' and NAs' knowledge of evidence-based neuro-protective nursing care is critical to optimizing the care of patients with moderate or severe TBI, reducing deaths, disabilities, and healthcare costs (Craig \& Stevens, 2011; Melnyk \& Fineout-verholt, 2015). However, the current state of knowledge of Thai trauma RNs and NAs is poorly understood. It is not known whether there are areas of knowledge that need to be addressed, in order to improve the quality of TBI care in Thailand. Therefore, the aim of this study was to investigate current knowledge of Thai RNs and NAs regarding the evidence-based principles of neuro-protective nursing care of patients with moderate or severe TBI.

\section{METHODS}

This article is protected by copyright. All rights reserved. 


\section{Design}

This was a descriptive survey study.

\section{Setting}

This study was conducted in the trauma ward at a regional hospital in Southern

Thailand. The hospital is a level I trauma center that provides care for around 20,751

patients per year. In 2016, which is when the study was conducted, 5,131 trauma

patients were admitted to the hospital; 2,082 cases were patients with TBI and $10.6 \%$

of patients with TBI died during their hospitalization (Annual hospital statistical report, 2016). Around $50 \%$ of those TBI patients from the ED were admitted to the 6 -bed trauma unit located within the 37-bed trauma ward. The trauma unit typically admits multiply injured patients, including patients with moderate or severe TBI, from ED. The patients will remain in the trauma unit for approximately 48 hours, before being transferred to another department such as the neurosurgical intensive care unit (ICU). Patients needing surgery and post-operative critical care nursing, will return to trauma unit because of the limited number of neurosurgical ICU beds. Patients in the 6-bed trauma unit are cared by two RNs and one or two NAs over each nursing shift. The 22 RNs and 13 NAs working in trauma ward can be allocated to the trauma unit.

This article is protected by copyright. All rights reserved. 


\section{Sample}

Convenience sampling was used to invite all trauma ward RNs and NAs to participate in the study using face-to-face invitation at routine nursing staff meetings. Although NAs have different responsibilities to RNs in the care of patients with moderate or severe $\mathrm{TBI}$, the NAs have crucial involvement in neuro-protective nursing care as described previously. Therefore, all trauma RNs and NAs were invited to participate in the study.

\section{Data collection}

A specifically designed data collection instrument was used to address the study aim:

“Trauma nurses' and nursing assistants' knowledge of neuro-protective nursing care survey". The survey used items, with permission, from the "Survey of emergency nurses' characteristics and management of patients with severe TBI" that was developed for a study of TBI care in the Thai ED setting (Damkliang, 2014). Information was collected about RNs' and NAs' characteristics (age, gender, highest level of nursing education, years of experience in nursing, years of experience in trauma nursing, and specific training in critical nursing or trauma nursing). The survey administered to the RNs consisted of 20 multiple-choice questions (MCQs), and NAs were required to complete five MCQs as their level of educational preparation is different to that of RNs.

Ten MCQs used by Damkliang (2014) that had a point-biserial correlation coefficient $\left(r_{p b}\right)$ of 0.25 or higher were chosen for inclusion in this study. The other ten 
MCQs were developed specifically for this study by the researchers based on a literature review of Guidelines for the Management of Severe Traumatic Brain Injury that have been published by the Brain Trauma Foundation (Carney et al., 2016), Best Practices in the Management of Traumatic Brain Injury that was published by American College of Surgeons (2015), and other evidence-based guidelines that are related to critical nursing care for patients with moderate or severe TBI (Alvis-Miranda, CastellarLeones, \& Moscote-Salazar, 2014; American Association for Respiratory Care, 2010; Barr et al., 2013; O'Driscoll, Howard, Earis, \& Mak, 2017; Mcivoy \& Meyer, 2009; National Institute for Health and Care Excellence, 2014; Schug, Palmer et al., 2015; Victorian State Trauma System, 2014). Twenty MCQs covered three core elements of neuro-protective nursing care: respiratory management ( $Q$ 1-8), hemodynamic management ( $Q$ 9-11), and ICP management ( $Q$ 12-20). Of these, five MCQs were drawn for NAs, including one MCQ related to respiratory management, one $\mathrm{MCQ}$ related to hemodynamic management, and three ICP management. All MCQs were developed specifically for neuro-protective nursing care of patients with moderate or severe TBI. Patients with moderate or severe TBI was not indicated in MCQs 5, 6, and 7 which are related to causes of hypercapnia and endotracheal suctioning as these core concepts are not different between ventilated patients with TBI and other groups of ventilated patients. However, evidence-based knowledge about causes of hypercapnia and endotracheal suctioning are important for the initial neuro-protective nursing care. 
The survey was initially written in English. Content and face validity of the English version were established by four Australian experts: one professor of nursing who is expert in the emergency nursing care and MCQ development; one professor of nursing who is expert in critical care nursing, and two lecturers in nursing who are experts in neuro-trauma critical care nursing. Three of the expert panel had experience of visiting Thai hospitals so were aware of the context of care.

As the participants in this study were Thai trauma RNs and NAs whose first language is Thai, the English survey was translated into Thai by the researcher. The Thai survey was then back-translated from Thai into English by a nursing lecturer from a Thai university who holds a PhD in nursing (written in English) and who is an expert in trauma care and TBI management. The content and face validity of the Thai survey was established by three Thai experts. The Thai expert panel consisted of two nursing lecturers who are experts in emergency neuro-trauma nursing and neuro-critical care and one neurosurgeon. Australian and Thai experts were asked to complete a content validity index (CVI) using a 4-point rating scale of not relevant (1 point), somewhat relevant ( 2 points), quite relevant ( 3 points) and highly relevant ( 4 points) (Polit \& Beck, 2008). The average item CVI of both English and Thai surveys was 0.81 , which is an acceptable value for relevance of the content validity (Polit \& Beck, 2008).

The Thai version of the survey was pilot-tested with RNs from the neurosurgical ICU and NAs from neurosurgical ward to establish reliability. The pilot-test was conducted on two occasions as five questions had poor discrimination. An item-to- 
total correlation was calculated to statistically establish item discrimination of MCQs by analyzing the relationship between each MCQ and the total test score (Considine, Botti, \& Thomas, 2005). Point biserial coefficients were calculated using the Pearson correlation coefficient formula: a $r_{p b}$ of 0.25 or higher was acceptable (Jackson \& Furnham, 2000). Five MCQs with poor discrimination on the first pilot-test were modified, keeping the core concept and the correct answer the same, then retested. Only items with a $r_{p b}$ of 0.25 were included in the final survey.

A paper-based survey was distributed to trauma ward RNs and NAs between 27 and 31 March 2017. All RNs and NAs were requested to complete the survey within their shift: this was a deliberate strategy so that nurses could not use resources such as textbooks, journal articles or discussions with expert clinicians. Nurses who completed the survey were specifically requested not to discuss it with colleagues who were yet to complete their surveys. Most nurses $(n=29,83 \%)$ finished the survey whilst on shift. Six nurses (17\%) needed to finish their survey at home and returned the survey to the researcher directly or via a mailbox located in trauma ward.

\section{Data analysis}

Data were analyzed using SPSS Version 23.0 for Windows ${ }^{\circledR}$ (IBM Inc., Chicago, IL, USA). All statistical tests were interpreted using a p<0.05 significance level (Heavey, 2011). Descriptive statistics were used to examine participant characteristics. Relationships 
between variables were analyzed using a point-biserial correlation coefficient for itemto-total correlations as data were nominal, ordinal, or not normally distributed (Gray, 2018).

\section{Ethical considerations}

Ethical approval was obtained from the Human Research and Ethics Committee (HREC) at XXXX [redacted for anonymity] (Approval No: 2016-303) and the Ethics Committee on Human Research of the study hospital in Thailand (Approval No: 95/2559).

Participants were invited to participate in the study by the researcher who is not involved in the management or leadership position of the trauma ward and the study hospital. Participants received written and verbal information on the aim, procedure, anonymity, and confidentiality aspects of the study. The researcher also mentioned that their participation was voluntary. All trauma ward RNs and NAs gave written informed consent.

\section{RESULTS}

All participants returned surveys, giving a response rate of $100 \%$. The median age of participants was 26.0 years (IQR=24.0-28.0). The median nursing experience of participants was 3.0 years $(I Q R=1.1-5.1)$, while the median trauma ward experience was 2.1 years (IQR=1.0-3.0). All RNs completed a four-year bachelor of nursing degree.

This article is protected by copyright. All rights reserved. 
Only one RN held a postgraduate qualification in critical care or trauma care. Eight of NAs had undertaken a six-month diploma and the remaining five NAs had completed high school grade 12 but had not completed any certificates related to nursing. The characteristics of participants are shown in Table 1.

**Table 1 here

\section{Overall test score}

The median score for the RN test was $13(I Q R=10.75-15)$ and the median score for the NA test was $3(I Q R=2-3)$. The item-to-total correlation for each MCQ is shown in Table 2. Questions 6, 8, 11, 13 and 18 had low item-to-total correlations, with a $r_{p b}$ less than 0.25. Two questions (Q1, Q5) had a negative correlation, indicating that these questions were given incorrect answers by nurses who otherwise performed well, or given the correct answer from nurses who otherwise performed poorly in an overall test score. A deliberate decision was made to consider the results of questions 1 and 5 despite the negative item-to-total correlation, as it was very likely that carbon dioxide monitoring and causes of hypercapnia were new concepts for the trauma nurses, as carbon dioxide monitoring is not the usual practice in the trauma ward.

**Table 2 here

Test scores by specific elements of knowledge

This article is protected by copyright. All rights reserved. 
The survey responses according to the three major elements of the initial neuroprotective nursing care for patients with moderate or severe TBI are shown in Table 3. The highest percentage of correct responses occurred for the question about abnormal urine output (Q11), which was a nursing task that usually performed in trauma ward. The other areas of knowledge that had high percentages of correct responses ( $\geq 80 \%)$, were administering $0.9 \%$ Sodium Chloride (Q10), appropriate actions for nurses to take after noting that a patient suddenly developed a fixed and dilated pupil (Q12), and patient positioning (Q16). There were seven MCQs with the correct responses of less than $50 \%$ (13.6-45.5\%) in three elements of knowledge tested, which were related to physiology and evidence-based practice. The MCQs with low correct responses in respiratory management element were related to end-tidal carbon dioxide $\left(\mathrm{ETCO}_{2}\right)$ monitoring (Q1), implications and causes of hypercapnia (Q4, Q5), and indications for endotracheal suctioning (Q7). In hemodynamic management, the target values of mean arterial pressure for patients with increased ICP to ensure sufficient CPP (Q9) were poorly understood. In ICP management, the MCQs with low correct responses were the use of sedatives and analgesics (Q18), and hyperthermia management (Q20). **Table 3 here

\section{DISCUSSION}

This article is protected by copyright. All rights reserved. 
This study took place in the trauma ward of a hospital in Southern Thailand where trauma RNs and NAs play a key role in caring for patients following initial moderate or severe TBI. As mentioned previously, RNs' and NAs' knowledge is the key to the effective initial neuro-protective nursing care of patients with moderate or severe TBI. The results of this study indicated knowledge deficits in all three elements of neuroprotective nursing care. Most areas of knowledge deficit were found as evidencepractice gaps in the trauma ward. For example, the knowledge of $\mathrm{ETCO}_{2}$ monitoring and cause of hypercapnia were poor, while carbon dioxide monitoring was not performed in the trauma ward (Promlek, 2019). Hyperthermia was another area of knowledge deficit and poor management in the trauma ward. Around $82 \%$ of patients with moderate or severe TBI admitted to the trauma ward experienced hyperthermia, while a low percentage of nursing management on hyperthermia was shown and nursing interventions provided to the patients were not based on the evidence (Promlek, 2019). Thus, there is a need for further improvement on the areas of knowledge deficit of trauma RNs and NAs in order to optimize the initial neuroprotective nursing care of patients with moderate or severe TBI.

A possible explanation for limited knowledge of trauma ward RNs and NAs is the low number of nurses who held postgraduate qualifications in critical care or trauma care. All RNs had Bachelors' degrees, but $98 \%$ of RNs did not have any specialty degrees. Previous studies found that nurses with a Bachelor's degree who have not obtained specialist training perceived that they have inadequate knowledge which can 
influence their confidence to perform specific care tasks for patients with moderate or severe TBI in critical care (Madhuvu, Plummer, \& Morphet, 2018; Oyesanya, Brown, \& Turkstra, 2017). Specialist training programs regarding the management of patients with severe TBI or obtaining additional certification in neuroscience nursing improved nurses' knowledge and evidence-based practice in neuro-protective nursing care (Damkliang, 2014; Rockett, Blissitt, \& Thompson, 2015). Thus, training programs for trauma RNs and NAs, specifically tailored to address their knowledge deficits are recommended to advanced their knowledge and improve their ability to deliver neuroprotective nursing care based on evidence.

Trauma ward nurses had considerable knowledge limitations of the evidencebased practices of $\mathrm{ETCO}_{2}$ monitoring and procedures for assessment and management of pain and agitation. Nurses' knowledge of the evidence underpinning effective care for patients with moderate or severe TBI is important, as nurses' knowledge has a relationship with the quality and safety care delivered (Smeland, Twycross, Lundeberg, \& Rustøen, 2018). Lack of knowledge of evidence to underpin nursing practice is not only a problem for Thai trauma nurses, but has been reported in other countries such as South Africa, Iran, and Malawi (Jordan, Bowers, \& Morton, 2016; Khammarnia, Haj Mohammadi, Amani, Rezaeian, \& Setoodehzadeh, 2015; Mulenga \& Naidoo, 2017). Postgraduate education enables nurses to attain advanced levels of evidence-based knowledge and therefore engage in evidence-based practice at a level higher than undergraduate nurses (Gijbels, O'Connell, Dalton-O'Conner, \& O'Donovan, 2010; Gill, 
Leslie, Grech, \& Latour, 2013; Rockett et al., 2015). Thus, to improve trauma nurses' knowledge of evidence to guide neuro-protective nursing care of patients with moderate or severe $\mathrm{TBI}$, the hospital and trauma ward should aim at increasing access to postgraduate education in nursing.

The initial neuro-protective nursing care content of undergraduate nursing curriculum in Southern Thailand is clearly inadequate to prepare nurses to deliver safe care for patients with moderate or severe TBI in critical care settings (Promlek, 2019). The complex concepts contents of neuro-protective nursing care of patients with moderate or severe TBI are taught in only two hours of classroom lecture (Promlek, 2019). It is difficult for nurses to understand and apply their knowledge in practice when such didactic teaching strategies are used. The current educational structures also mean that students do not have sufficient experience in caring for patients with moderate or severe TBI in critical care. Lack of direct patient care experience is challenging for nursing students to develop experiential knowledge and apply theoretical knowledge, as learning illustrated by real cases in clinical fields assists students in expanding critical thinking (Jasemi, Whitehead, Habibzadeh, Zabihi, \& Rezaie, 2018). Thus, it is difficult for nursing students who lack direct care experience of patients with moderate or severe TBI to develop, apply, and sustain their knowledge of neuro-protective nursing care.

Around $40 \%$ of NAs on the trauma ward had not completed any educational preparation related to nursing. The other $60 \%$ of NAs had completed a six-month 
diploma focused on performing procedures in general patients without detailed rationales, which caused NAs had limited knowledge of neuro-protective nursing care of patients with moderate or severe TBI. Thailand faces critical shortages of RNs as a result of an ageing nursing workforce, a high rate of intention to leave the nursing profession, and a low number of new entry nurses (Krisada et al., 2016; Sasat \& Bowers, 2013). The Thai Ministry of Public Health (2016) has a policy and workforce strategic framework for hospitals to employ and manage non-RNs. The purpose of employing NAs is to help patients with basic personal care with the intent of reducing RNs' workload; however, high NAs staffing has been associated with increased mortality (Griffiths et al., 2018). The quality of care provided by NAs is lower than nursing care provided by RNs due to NAs have a lower level of educational preparation and knowledge than RNs (Karacsony, Good, Chang, Johnson, \& Edenborough, 2019; Smets et al., 2018). Smets et al. (2018) also concluded that RNs have a better knowledge of palliative care than NAs as these RNs having undertaken formal training in palliative care. Therefore, the provision of adequate training and education for NAs, specifically tailored to their knowledge deficit (hyperthermia management) should be a priority of trauma ward to improve NAs' knowledge and ability to provide safe care for patients with moderate or severe TBI, and also to increase NAs capacity to support RNs in their role in care delivery for these vulnerable patients.

Lack of evidence-based practice guidelines for neuro-protective nursing care of patients with moderate or severe TBI in trauma ward might be another explanation for 
the knowledge deficit of trauma nurses and NAs in this study. A study in a Thai ED with no evidence-based guidelines to guide ED nurses' management of patients with severe TBI also reported knowledge deficits of nurses regarding severe TBI management (Damkliang, Considine, Kent, \& Street, 2014). However, after the implementation of an evidence-based care bundle for severe TBI management, there was an improvement in these Thai ED nurses' knowledge regarding severe TBI management (Damkliang, Considine, Kent, \& Street, 2015). Other studies also highlighted that use of evidencebased guidelines or care bundles improved nurses' knowledge (Ruksakun, Boonkartrum, Mepraseart, \& Kraibut, 2013; Subramanian, Choy, Gobal, Mansor, \& Ng, 2013). Thus, evidence-based practice tools to guide the initial neuro-protective nursing care of patients with moderate or severe TBI are needed to improve trauma ward nurses' knowledge which influences the quality of care.

\section{Limitations}

Several limitations were identified in this study. First, $17 \%$ of RNs and NAs took the knowledge surveys away and then returned the survey to the researcher. It was possible that textbooks or other resources were used although instructions to the contrary. Given that all participants still had areas of knowledge deficit in their survey results, it is unlikely that additional resources were used. Thus, these participants were not excluded from the study. Second, although all participants were allocated to care of patients in the trauma unit, the frequency of participants to care of patients with 
moderate or severe TBI was not assessed. Third, nurses were not assessed if they received neuro-protective nursing care training from nursing schools, which can affect their knowledge. Fourth, three MCQs were not specific to patients with TBI which may not have been clear enough for the participants to focus on neuro-protective nursing care. Finally, the study sample is only trauma ward RNs and NAs that might not represent the population of all Thai trauma nurses. Further research should recruit trauma nurses from hospitals in a similar context and further refinement of the knowledge survey used in this study is needed.

\section{CONCLUSION}

This study of knowledge of initial neuro-protective nursing care of patients with moderate or severe TBI of Thai trauma RNs and NAs showed areas of knowledge deficit that is disadvantageous for quality of care. Educational interventions specifically tailored to RNs' and NAs' knowledge deficits, RNs undertaking postgraduate education, and implementation of evidence-based practice tools to guide neuro-protective nursing care are recommended to advance their knowledge, which in turn help to improve the safety and quality of care for Thai patients with moderate or severe TBI.

This article is protected by copyright. All rights reserved. 


\section{REFERENCES}

This article is protected by copyright. All rights reserved. 
Alvis-Miranda, H. R., Castellar-Leones, S. M., \& Moscote-Salazar, L. R. (2014). Intravenous fluid therapy in traumatic brain injury and decompressive craniectomy. Bulletin of Emergency and Trauma, 2(1), 3-14.

American Association for Respiratory Care. (2010). Endotracheal suctioning of mechanical ventilated patients with artificial airways. Respiratory Care, 55, 758764.

American College of Surgeons. (2015). Best practices in the management of traumatic brain injury. Retrieved from https://www.facs.org/-/media/files/qualityprograms/trauma/tqip/tbi_guidelines.ashx?la=en

Barr, J., Fraser, G. L., Puntillo, K., Ely, E. W., Gélinas, C., Dasta, J. F., . . . Jaeschke, R. (2013). Clinical practice guidelines for the management of pain, agitation, and delirium in adult patients in the intensive care unit: executive summary. American Journal Of Health-System Pharmacy: AJHP: Official Journal Of The American Society Of Health-System Pharmacists, 70, 53-58.

doi:10.1093/ajhp/70.1.53

Bureau of Policy and Strategy, Thai Ministry of Public Health. (2017). Public Health Statistics A.D.2017. Retrieved from http://bps.moph.go.th/new_bps/sites/default/files/stratistics60.pdf Carney, N., Totten, A. M., O'Reilly, C., Ullman, J. S., Hawryluk, G. W. J., Bell, M. J., . . . Ghajar, J. (2016). Guidelines for the management of severe traumatic brain 
injury ( $4^{\text {th }}$ ed). Retrieved from https://braintrauma.org/guidelines/guidelinesfor-the-management-of-severe-tbi-4th-ed\#/

Considine, J., Botti, M., \& Thomas, S. (2005). Design, format, validity and reliability of multiple choice questions for use in nursing research and education. Collegian, $12,19-24$.

Craig, J. V., \& Stevens, K. R. (2011). Evidence-based practice in nursing. In J. V. Craig \& R. L. Smyth (Eds.), The evidence-based practice manual for nurses. [electronic resource] (pp. 3-23). Retrieved from http://www.deakin.eblib.com.AU/EBLWeb/patron/?target=patron\&extendedid $=\mathrm{P} 17216910$

Damkliang, J. (2014). Use of an evidence-based care bundle by Thai emergency nurses. (Doctoral dissertation), Retrieved from http://dro.deakin.edu.au/view/DU:30072992

Damkliang, J., Considine, J., Kent, B., \& Street, M. (2014). Initial emergency nursing management of patients with severe traumatic brain injury: Development of an evidence-based care bundle for the Thai emergency department context. Australasian Emergency Nursing Journal, 17, 152-160. doi:10.1016/j.aenj.2014.05.005

Damkliang, J., Considine, J., Kent, B., \& Street, M. (2015). Using an evidence-based care bundle to improve Thai emergency nurses' knowledge of care for patients with 
severe traumatic brain injury. Nurse Education in Practice, 15, 284-292. doi:10.1016/j.nepr.2015.03.007

Dewan, M. C., Rattani, A., Gupta, S., Baticulon, R. E., Hung, Y.-C., Punchak, M., . . Park, K. B. (2019). Estimating the global incidence of traumatic brain injury. Journal Of Neurosurgery, 130, 1080-1097. doi:10.3171/2017.10.JNS17352

Douglas, B., Morarty, J., \& Saxena, M. (2011). Traumatic brain injury. In K. Curtis, C. Ramsden, \& B. Lord (Eds.), Emergency and trauma care for nurses and paramedics (pp. 1169-1192): Chatswood, N.S.W. : Mosby Elsevier Australia.

Gijbels, H., O'Connell, R., Dalton-O'Conner, C., \& O'Donovan, M. (2010). A systematic review evaluating the impact of post-registration nursing and midwifery education on practice. Nurse Education in Practice, 10, 64-69. doi:10.1016/j.nepr.2009.03.011

Gill, F. J., Leslie, G. D., Grech, C., \& Latour, J. M. (2013). Health consumers' experiences in Australian critical care units: postgraduate nurse education implications. Nursing in Critical Care, 18, 93-102. doi:10.1111/j.1478-5153.2012.00543.x

Gray, D. E. (2018). Doing research in the real world ( $4^{\text {th }}$ ed.): London; Thousand Oaks, California: SAGE Publications.

Griffiths, P., Recio-Saucedo, A., Dall'Ora, C., Briggs, J., Maruotti, A., Meredith, P., . . . Ball, J. (2018). The association between nurse staffing and omissions in nursing care: A systematic review. Journal of Advanced Nursing, 74, 1474-1487. doi:10.1111/jan.13564

This article is protected by copyright. All rights reserved. 
Heavey, E. (2011). Sampling methods: does the sample represent the population? In A. Sibley (Ed.), Statistics for nursing: a practical approach (pp. 63-74): Sudbury, MA: Jones \& Bartlett Learning.

Hurst, K. (2010). How much time do nurses spend at the bedside? Nursing Standard, 24, 14. doi: 10.7748/ns.24.52.14.s20

Jackson, C. J., \& Furnham, A. (2000). Designing and analysing questionnaires and surveys: a manual for health professionals and administrators: London: Whurr. Jasemi, M., Whitehead, B., Habibzadeh, H., Zabihi, R. E., \& Rezaie, S. A. (2018). Challenges in the clinical education of the nursing profession in Iran: A qualitative study. Nurse Education Today, 67, 21-26. doi:10.1016/j.nedt.2018.04.010

Jordan, P., Bowers, C., \& Morton, D. (2016). Barriers to implementing evidence-based practice in a private intensive care unit in the Eastern Cape. Southern African Journal of Critical Care, 32, 50-54. doi:10.7196/SAJCC.2016.v32i2.253

Karacsony, S., Good, A., Chang, E., Johnson, A., \& Edenborough, M. (2019). An instrument to assess the education needs of nursing assistants within a palliative approach in residential aged care facilities. BMC Palliative Care, 18, 115. doi:10.1186/s12904-019-0447-0

Khammarnia, M., Haj Mohammadi, M., Amani, Z., Rezaeian, S., \& Setoodehzadeh, F. (2015). Barriers to implementation of evidence-based practice in Zahedan 
teaching hospitals, Iran, 2014. Nursing Research and Practice, 2015, 1-5. doi:10.1155/2015/357140

Krisada, S., Viroj, T., Tuangtip, T., Petsunee, T., Wilaiphorn, T., Panuwat, P., . . Bandit, T. (2016). Thai nurse cohort study: cohort profiles and key findings. $B M C$ Nursing, 15, 1-12. doi:10.1186/s12912-016-0131-0

Madhuvu, A. E., Plummer, V., \& Morphet, J. (2018). An exploration of participants' experience of an intensive care nursing transition to specialty practice program. Australian Critical Care, 31(5), 311-316. doi:10.1016/j.aucc.2017.08.005

Massenburg, B. B., Veetil, D. K., Raykar, N. P., Agrawal, A., Roy, N., \& Gerdin, M. (2017). A systematic review of quantitative research on traumatic brain injury in India. Neurology India, 65, 305-314. doi:10.4103/neuroindia.NI_719_16

Mcilvoy, L., \& Meyer, K. (2009). Nursing management of adults with severe traumatic brain injury. Retrieved from http://www.aann.org/pdf/cpg/aanntraumaticbraininjury.pdf Melnyk, B. M., \& Fineout-verholt, E. (2015). Making the case for evidence-based practice and cultivating a spirit of inquiry. In B. M. Melnyk \& E. FineoutOverholt (Eds.), Evidence-based practice in nursing and healthcare: a guide to best practice (3rd ed.): Philadelphia: Wolters Kluwer Health.

Mulenga, C., \& Naidoo, J. R. (2017). Nurses' knowledge, attitudes and practices regarding evidence-based practice in the prevention of mother-to-child 
transmission of HIV programme in Malawi. Curationis, 40, 1-8. doi: 10.4102/curationis.v40i1.1656.

National Institute for Health and Care Excellence. (2014). Head injury, Triage, assessment, investigation and early management of head injury in children, young people and adults. Retrieved from http://dx.doi.org/10.1136/bmj.g409

National Statistical Office of Thailand. (2019). Hospital mortality and significant causes of mortality: $10^{\text {th }}$ edition (2013-2017). Retrieved from http://statbbi.nso.go.th/staticreport/page/sector/th/05.aspx

O'Driscoll, B. R., Howard, L. S., Earis, J., \& Mak, V. (2017). British Thoracic Society Guideline for oxygen use in adults in healthcare and emergency settings. BMJ Open Respiratory Research, 4, e000170-e000170. doi:10.1136/bmjresp-2016000170

Office of Transport and Traffic Policy and Planning, Ministry of Transport, Thailand. (2019). The report on road transport status in Thaiand (2018). Retrieved from http://www.otp.go.th/uploads/tiny_uploads/PDF/256209/25620916Accident\%20report2561\%20_OTP.pdf

Oyesanya, T. O., Brown, R. L., \& Turkstra, L. S. (2017). Caring for Patients with traumatic brain injury: a survey of nurses' perceptions. Journal of Clinical Nursing, 26, 1562-1574. doi:10.1111/jocn.13457

Panahi, Y., Mojtahedzadeh, M., Najafi, A., Rajaee, S. M., Torkaman, M., \& Sahebkar, A. (2018). Neuroprotective Agents in the Intensive Care Unit: - 
Neuroprotective Agents in ICU. Journal Of Pharmacopuncture, 21, 226-240. doi:10.3831/KPI.2018.21.026

Panjaisri, S., Phuenpathom, N., \& Veerasan, K. (2013). Clinical practice guidelines for traumatic brain injury. Retrieved from http://www.google.co.th/url?sa=t\&rct=j\&q=\&esrc=s\&source=web\&cd=1\&ved= OahUKEwjRy57jtLPNAhVCGZQKHZbAAn8QFggfMAA\&url=http\%3A\%2F\%2Fwww .med.cmu.ac.th\%2Fdept\%2Fsurgery\%2Fneurosurgerycmu\%2F2011\%2Fimages \%2FDocuments\%2Fclinical-practice-guidelines-for-traumatic-braininjury.pdf\&usg=AFQjCNGj2gC61FRVQ3LKWd_mQxEKHic8Q\&sig2=oEiy84SrE36YRalEtN0v3Q

Polit, D. F., \& Beck, C. T. (2008). Nursing research: generating and assessing evidence for nursing practice (8th ed.): Philadelphia: Wolters Kluwer Health/Lippincott Williams \& Wilkins.

Promlek, K. (2019). Evidence-Based Care for Traumatic Brain Injury Patients by Thai Trauma Nurses. (Doctoral dissertation), Deakin University.

Rockett, H., Blissitt, P. A., \& Thompson, H. J. (2015). Fever management practices of neuroscience nurses: What has changed? Journal of Neuroscience Nursing, 47, 66-75. doi:10.1097/JNN.0000000000000118

Ruksakun, P., Boonkartrum, N., Mepraseart, B., \& Kraibut, K. (2013). Effect of developing a bundle of care for the prevention of ventilator associated pneumonia in SakonNakhon hospital. Sakon Nakhon hospital, 16, 11-19.

This article is protected by copyright. All rights reserved. 
Sasat, S., \& Bowers, B. J. (2013). Spotlight Thailand. Gerontologist, 53, 711-717. doi:geront/gnt038

Schug, S. A., Palmer, G. m., Scott, D. A., Halliwell, R., \& Trinca, J. (2015). Acute pain management: scientific evidence ( $4^{\text {th }}$ ed). Retrieved from http://fpm.anzca.edu.au/documents/apmse4_2015_final

Smeland, A. H., Twycross, A., Lundeberg, S., \& Rustøen, T. (2018). Nurses' knowledge, attitudes and clinical practice in pediatric postoperative pain management. Pain Management Nursing, 19, 585-598.

doi:10.1016/j.pmn.2018.04.006

Smets, T., Pivodic, L., Piers, R., Pasman, H. R. W., Engels, Y., Szczerbińska, K., . . Van den Block, L. (2018). The palliative care knowledge of nursing home staff: The EU FP7 PACE cross-sectional survey in 322 nursing homes in six European countries. Palliative Medicine, 32, 1487-1497. doi:10.1177/0269216318785295

Subramanian, P., Choy, K. L., Gobal, S. V., Mansor, M., \& Ng, K. H. (2013). Impact of education on ventilator-associated pneumonia in the intensive care unit. Singapore Medical Journal, 54, 281-284. doi: 10.11622/smedj.2013109

Thai Ministry of Public Health. (2016). Workforce plan for practical nurses. Retrieved from http://www.nursing.go.th/?page_id=60\&page=3

Varghese, R., Chakrabarty, J., \& Menon, G. (2017). Nursing management of adults with severe traumatic brain injury: A narrative review. Indian Journal of Critical Care Medicine, 21, 684-697.doi:10.4103/ijccm.IJCCM_233_17

This article is protected by copyright. All rights reserved. 
Victorian State Trauma System. (2014). Traumatic brain injury guideline. Retrieved from

http://trauma.reach.vic.gov.au/sites/default/files/Traumatic\%20Brain\%20Injur y\%20Guideline\%20Guideline_Ver\%201.0_250914_complete.pdf

World Health Organization. (2018). Global status report on road safety: support a decade of action. Retrieved from https://www.who.int/news-room/factsheets/detail/road-traffic-injuries

Table 1. Participant characteristics $(n=35)$

$\begin{array}{lll}\text { Demographic data } & \mathrm{n} & \%\end{array}$

\section{Gender}

Female

Male

4

11.4

\section{Age (yrs)}

$20-26$ 
Table 1. Participant characteristics $(n=35)$

\section{Demographic data}

n

$\%$

\section{Education}

Bachelor of Nursing

22

62.8

A six-month diploma

8

22.9

Had not completed any nursing certificate

5

14.3

Experience in nursing (yrs)

$<6$

29

82.9

$7-12$

2

5.7

$13-24$

4

11.4

Experience in trauma nursing (yrs)

$<1$

$1-2$

$>2$
8

9

18
22.9

25.7

51.4

\section{Short course training in trauma care}

No

Yes-critical nursing care (4 months)

Role
34

97.1

1

2.9

Registered nurse 
Table 1. Participant characteristics $(n=35)$

\section{Demographic data}

n

$\%$

Nursing assistant

13

37.1

This article is protected by copyright. All rights reserved. 
Table 2. Item discrimination analysis (item-to-total correlation for MCQs)

\begin{tabular}{|c|c|c|c|c|c|}
\hline \multirow[t]{2}{*}{ Item } & \multicolumn{2}{|c|}{ Correct responses } & \multicolumn{2}{|c|}{ Incorrect responses } & \multirow{2}{*}{$\begin{array}{c}\text { Point-biserial correlation } \\
\text { coefficient }\end{array}$} \\
\hline & $n$ & (\%) & $n$ & (\%) & \\
\hline 1 & 5 & 22.7 & 17 & 77.3 & -0.082 \\
\hline 2 & 14 & 63.6 & 8 & 22.9 & 0.467 \\
\hline 3 & 16 & 72.7 & 6 & 27.3 & 0.399 \\
\hline 4 & 10 & 45.5 & 12 & 54.5 & 0.639 \\
\hline 5 & 3 & 13.6 & 19 & 86.4 & -0.071 \\
\hline $6^{*}$ & 30 & 85.7 & 5 & 14.3 & 0.038 \\
\hline 7 & 7 & 31.8 & 15 & 68.2 & 0.538 \\
\hline 8 & 15 & 68.2 & 7 & 31.8 & 0.016 \\
\hline 9 & 4 & 18.2 & 18 & 81.8 & 0.426 \\
\hline 10 & 20 & 90.9 & 2 & 9.1 & 0.355 \\
\hline $11^{*}$ & 33 & 94.3 & 2 & 5.7 & 0.123 \\
\hline 12 & 20 & 90.9 & 2 & 9.1 & 0.355 \\
\hline 13 & 18 & 81.8 & 4 & 18.2 & 0.100 \\
\hline 14 & 18 & 81.8 & 4 & 18.2 & 0.339 \\
\hline 15 & 19 & 86.4 & 3 & 13.6 & 0.286 \\
\hline $16^{*}$ & 32 & 91.4 & 3 & 8.6 & 0.398 \\
\hline $17^{*}$ & 19 & 54.3 & 16 & 45.7 & 0.733 \\
\hline
\end{tabular}

This article is protected by copyright. All rights reserved. 
Table 2. Item discrimination analysis (item-to-total correlation for MCQs)

\begin{tabular}{lccccc}
\hline & \multicolumn{2}{l}{ Item } & \multicolumn{2}{c}{ Correct responses } & \multicolumn{2}{c}{ Incorrect responses } & Point-biserial correlation \\
\cline { 2 - 4 } & $n$ & $(\%)$ & $n$ & $(\%)$ & coefficient \\
\hline 18 & 7 & 31.8 & 15 & 68.2 & $\mathbf{0 . 1 0 3}$ \\
19 & 15 & 68.2 & 7 & 31.8 & 0.372 \\
$20 *$ & 12 & 34.3 & 23 & 65.7 & 0.648 \\
$*$ &
\end{tabular}

This article is protected by copyright. All rights reserved. 
Table 3. Percentage of correct response in each item and element of knowledge

1. Respiratory management

Q1: $\mathrm{ETCO}_{2}$ is the most reliable method for monitoring ventilation and confirmation of endotracheal tube placement

Q2: Best $\mathrm{PaCO}_{2}$ targets for moderate or severe TBI

Q3: Implications of hypocapnia in moderate or severe TBI

Q4: Implications of hypercapnia in moderate or severe TBI

Q5: Cause of hypercapnia in ventilated patients

Q6*: Essential action to perform during endotracheal suctioning

Q7: Indications for endotracheal suctioning

Q8: Best oxygenation values for moderate or severe TBI

2. Hemodynamic management

Q9: Best values of MAP for patients with increased ICP to ensure sufficient cerebral perfusion pressure

Q10: Rationale for giving $0.9 \%$ Sodium Chloride for patients with $90.9(20)$ moderate or severe TBI

Q11*: Abnormal values of urine output

3. ICP management

This article is protected by copyright. All rights reserved. 
Table 3. Percentage of correct response in each item and element of knowledge

\section{Elements and items of knowledge}

Correct response

$\%(n)$

Q12: Most appropriate action for nurses to take after noting that a patient suddenly developed a fixed and dilated pupil

Q13: Patterns that indicate increasing ICP in the brain stem

following moderate or severe TBI

Q14: Reasons for giving mannitol in moderate or severe TBI

Q15: Indications to withhold 20\% mannitol and notify the physician when patients are ordered repeated administration of $20 \%$ mannitol $100 \mathrm{ml}$ iv every 8 hours

Q16*: Best position for moderate or severe TBI

Q17*: Most immediate life-threatening complication of a rigid cervical collar in patients with newly acquired moderate or severe TBI

Q18: Use of sedatives and analgesics in newly acquired moderate or severe $\mathrm{TBI}$

Q19: Pathophysiology of hyperthermia that causes increased ICP

Q20*: Best management of hyperthermia in moderate or severe TBI
$81.8(18)$

$86.4(19)$

$54.3(19)$

$31.8(7)$

$68.2(15)$

$34.3(12)$

This article is protected by copyright. All rights reserved. 
Table 3. Percentage of correct response in each item and element of knowledge

Abbreviation: $\mathrm{ETCO}_{2}$, End-tidal carbon dioxide; $\mathrm{MAP}$, mean arterial pressure

$\mathrm{PaCO}_{2}$, Partial pressure of arterial carbon dioxide; $\mathrm{TBI}$, traumatic brain injury

* Questions with 35 respondents (registered nurses and nursing assistants); the remaining

Questions were tested on 22 registered nurses

This article is protected by copyright. All rights reserved. 


\title{
Thai trauma nurses' knowledge of neuro-protective nursing care of traumatic brain injury patients: A survey study
}

\author{
AUTHORS \\ Kesorn PROMLEK, RN, MNS (Adult Nursing) ${ }^{1,2}$ \\ Judy CURREY, RN, $\mathrm{PhD}^{1}$ \\ Jintana DAMKLIANG, RN, $\mathrm{PhD}^{2}$ \\ Julie CONSIDINE, RN, $\mathrm{PhD}^{1,3}$
}

${ }^{1}$ Deakin University Geelong, School of Nursing and Midwifery; Centre for Quality and Patient Safety Research; Institute for Health Transformation

${ }^{2}$ Faculty of Nursing, Prince of Songkla University, Thailand

${ }^{3}$ Centre for Quality and Patient Safety Research-Eastern Health Partnership, Box Hill, Victoria, Australia

\section{Correspondence}

Kesorn PROMLEK, School of Nursing and Midwifery, Deakin University, 221 Burwood Hwy, Burwood, Victoria 3125, Australia.

Email: kpromle@deakin.edu.au Tel.: +61 402885913

ORCID iD: Kesorn PROMLEK ID: https://orcid.org/0000-0002-1838-5522

\section{Author's institutional affiliations:}

- Faculty of Nursing, Prince of Songkla University, Thailand

- School of Nursing and Midwifery, Deakin University, Burwood campus, Australia (a PhD student)

This article is protected by copyright. All rights reserved. 
THAI TRAUMA NURSES' KNOWLEDGE

\section{Acknowledgements}

The authors would like to thank nurses and nursing assistants from trauma ward for their participation in this study, as well as the Nurse Director of the hospital, Head Nurse of trauma ward, and an advanced practice nurse of neurosurgical ICU for their support.

\section{Conflict of interest}

No conflict of interest has been declared by the authors.

\section{Funding information}

Ms Promlek is supported by a PhD scholarship from Deakin University, Australia and Faculty of Nursing, Prince of Songkla University, Thailand, and a 2019 Deakin University Faculty of Health Publication Award.

\section{Authorship statement}

We confirm that all listed authors meet the authorship criteria according to the latest guidelines of the Internatinal Committee of Medical Journal editors and that all authors are in agreement with the content of the manuscript. KP, JCo, JCu conceived the study concept and design. $\mathrm{KP}$ collected the data and drafted the manuscript. $\mathrm{KP}, \mathrm{JCo}$, JCu were responsible for analysis and interpretation of data. JCo, JCu, and JD were responsible for critical revisions to the manuscript for important intellectual content. All authors approved the final version for submission.

Word count: 3,898

This article is protected by copyright. All rights reserved. 


\section{University Library}

\section{- M M I N E R VA A gateway to Melbourne's research publications}

Minerva Access is the Institutional Repository of The University of Melbourne

Author/s:

Promlek, K;Currey, J;Damkliang, J;Considine, J

Title:

Thai trauma nurses' knowledge of neuroprotective nursing care of traumatic brain injury patients: A survey study.

Date:

2020-09

Citation:

Promlek, K., Currey, J., Damkliang, J. \& Considine, J. (2020). Thai trauma nurses' knowledge of neuroprotective nursing care of traumatic brain injury patients: A survey study.. Nurs Health Sci, 22 (3), pp.787-794. https://doi.org/10.1111/nhs.12730.

Persistent Link:

http://hdl.handle.net/11343/286971 